\title{
Factors Affecting the Response of Pomegranate Fruit to Alternaria alternata, the Causal Agent of Heart Rot
}

D. Ezra ${ }^{\dagger}$ and R. Shulhani, Department of Plant Pathology and Weed Research, Agricultural Research Organization (ARO), the Volcani Center, Rishon Le'Zion, 7528809 Israel; I. Bar Ya'akov, R. Harel-Beja, and D. Holland, ARO, Newe Ya'ar Research Center, P.O. Box 1021, Ramat Yishai, 30095 Israel; D. Shtienberg, Department of Plant Pathology and Weed Research, Agricultural Research Organization (ARO), the Volcani Center, Rishon Le'Zion, 7528809 Israel

\begin{abstract}
Heart rot, caused by Alternaria alternata, is a major pomegranate disease that impacts production worldwide; most fruits in orchards are colonized by A. alternata but, nevertheless, symptoms are apparent on only a small proportion of the colonized fruits. During the years of our previous research it was noticed that within individual orchards, the incidence of pomegranate fruits exhibiting heart rot symptoms was related to the visual appearance of the trees: trees that appeared visually frail bore more diseased fruits than robust trees. Furthermore, it was noticed that the disease responses of different pomegranate accessions and possibly of different variants of the same cultivar varied markedly. The specific objectives of the present study were: (i) to characterize the relationship between the visual appearance of pomegranate plants or individual stems and the incidence of heart rot and their vulnerability to heart rot; and (ii) to elucidate factors affecting the response of pomegranate fruit to $A$. alternata. Analysis of heart rot incidence in four orchards in 2014 revealed large differences in heart rot incidence among trees growing side

by side in the same orchard; these differences were related to the visual appearance of the pomegranate trees. There were significant differences among germination rates of A. alternata spores in juice prepared from asymptomatic fruits originating from these trees, and comparable differences were found among the acidity levels $(\mathrm{pH})$ of the juices. These differences may reflect differences among the physiological responses of pomegranate trees to heart rot. Fruits collected from the pomegranate collection located in Newe Ya'ar, which comprised 95 accessions in 2015 and 110 accessions in 2016, were also examined. There were differences among the acidity levels $(\mathrm{pH})$ of the juices produced from these fruits and among the germination rates of A. alternata spores in the juices. These differences may reflect variances among the genetic responses of pomegranate accessions to heart rot. Results of studying the relationship between the acidity levels of pomegranate juice and the germination rates of A. alternata spores supported the hypothesis that, apart from $\mathrm{pH}$, a compound(s) present in the juice regulates the germination of A. alternata spores in the juice.
\end{abstract}

Pomegranate (Punica granatum L., Lythraceae) is an ancient plant and fruit native to Central Asia; it is a multitrunk shrub with bushy appearance (Levin 2006). Fruit rot, also known as "heart rot" or "black heart," is a major disease that impacts pomegranate production worldwide (Day and Wilkins 2011; Holland et al. 2009; Tziros et al. 2008; Zhang and McCarthy 2012). Infected fruits are characterized by brown (soft) to black (dry) rot of the arils when opened, while the outer peel and the hard rind show no symptoms (Ezra et al. 2015). Fungal isolation from diseased fruits usually revealed Alternaria spp. and Aspergillus spp. (Michailides et al. 2008); Penicillium sp., Botrytis sp., and Rhizopus sp. were also isolated but in much lower incidences. Recently, it was reported that the causal agent is $A$. alternata (Fr.) Keissl. (Ezra et al. 2015; Michailides et al. 2008). In some cases, other Alternaria spp. could be identified (Luo et al. 2017). In addition, A. alternata may infect other organs of the pomegranate tree: in Turkey, Israel, and Spain, A. alternata caused lesions on leaves, flowers, and young fruits (Ezra et al. 2010; Pala et al. 2009; Tziros et al. 2008).

We have recently reported that $A$. alternata had colonized more than $80 \%$ of the pistils of asymptomatic fruits. Nevertheless, the

${ }^{\dagger}$ Corresponding author: D. Ezra; E-mail: dezra@ volcani.agri.gov.il

D. Ezra and R. Shulhani contributed equally to this article.

Funding: This work was partially financed by the Pomegranate Board of the Plants Production and Marketing Board of Israel, grant number 132-1795-15.

Contribution No. 576/17 from the Agricultural Research Organization, The Volcani Center, Rishon LeZion, 7528809 Israel.

Accepted for publication 11 August 2018.

() 2019 The American Phytopathological Society pathogen was isolated at much lower incidences (about 8\%) from the inner parts of the fruit including the tunnels and loculi of the fruits (Ezra et al. 2015). According to our findings, A. alternata spores penetrate the pistils of open flowers and grow into the tunnels that connect the pistils and the loculi. Then the pathogen progresses into the lower loculus where it remains latent until fruit ripening. When fruits mature, the pathogen resumes its growth in the lower loculus, invades the upper loculi, and cause rotting of the arils. Eventually, the entire fruit is infected and exhibits typical rot symptoms (Ezra et al. 2015). The etiology of the disease implies that suppression of heart rot by application of fungicides intended to prevent A. alternata from infecting the flowers is not practicable in commercial pomegranate production (Vincent et al. 2017) for several reasons. The stigma is the plant organ to be protected by fungicides. Nevertheless, directing fungicides to the stigmata of pomegranate flowers is difficult because it is located inside the flower crown, their size is minute, and orientation of the flowers within the tree canopy is uneven. Furthermore, during the blooming period (which may extend for up to 2 months), new flowers open daily, meaning that fungicides should be applied at frequent intervals for a relatively long period. It should also be noted that postharvest applications are not effective in preventing heart rot development in the fruit (Luo et al. 2017).

As most of the fruits in the orchards are colonized by A. alternata, there is potential for heart rot to develop in all of them. Nevertheless, symptoms are apparent on only a small proportion of the colonized fruits (Ezra et al. 2015). The reason why most fruits remain asymptomatic is not known, and explaining this phenomenon might help to devise means to prevent rot development and to suppress the disease. It was previously demonstrated that host physiology, rather than pathogen occurrence or environmental conditions, influence the development of core rot of Red Delicious apples which is caused by A. alternata (Shtienberg 2012). It is possible that pomegranate tree physiology governs the development of heart rot as well. During the years of our previous research, we have noticed that incidence of heart rot symptoms in pomegranate fruits within orchards was related to the visual appearance of the trees. Moreover, when pomegranates 
grow as multistem shrubs rather than single-trunk trees, occasionally there were differences in disease development even among individual stems of the same plant. Plants, or individual stems, that visually appeared to be frail, with sparse canopies and small, yellowish leaves, bore more diseased fruits than those with dense canopies and large, dark green leaves. During the years of our previous research, we also noticed that the disease responses of different pomegranate accessions, and possibly of different variants of the same cultivar, varied markedly. This observation may indicate that the genetic background of the host also is important. However, these observations were not verified experimentally.

The specific objectives of the present study were: (i) to characterize the relationship between the visual appearance of pomegranate plants or individual stems and the incidence of heart rot and to their vulnerability to heart rot; and (ii) to elucidate factors affecting the response of pomegranate fruit to A. alternata. Some of the results were presented recently by Ezra et al. (2017).

\section{Materials and Methods}

Criteria for tree classification. Occasionally, the vigor and visual appearance of pomegranate trees growing near to one another, in the same commercial orchard, differed markedly. Sometimes, this differentiation also was observed among individual trunks of a certain tree: some trees (or individual trunks) exhibited a robust appearance, with dense canopies and large, dark-green, shining leaves; others presented a frail appearance, with transparent (spare) canopies and small light-green, dull leaves (Fig. 1). Previous observations suggested that fruits with heart-rot symptoms developed more frequently on frail trees or trunks (referred to as physiologically susceptible) than on robust ones (referred to as physiologically resistant).
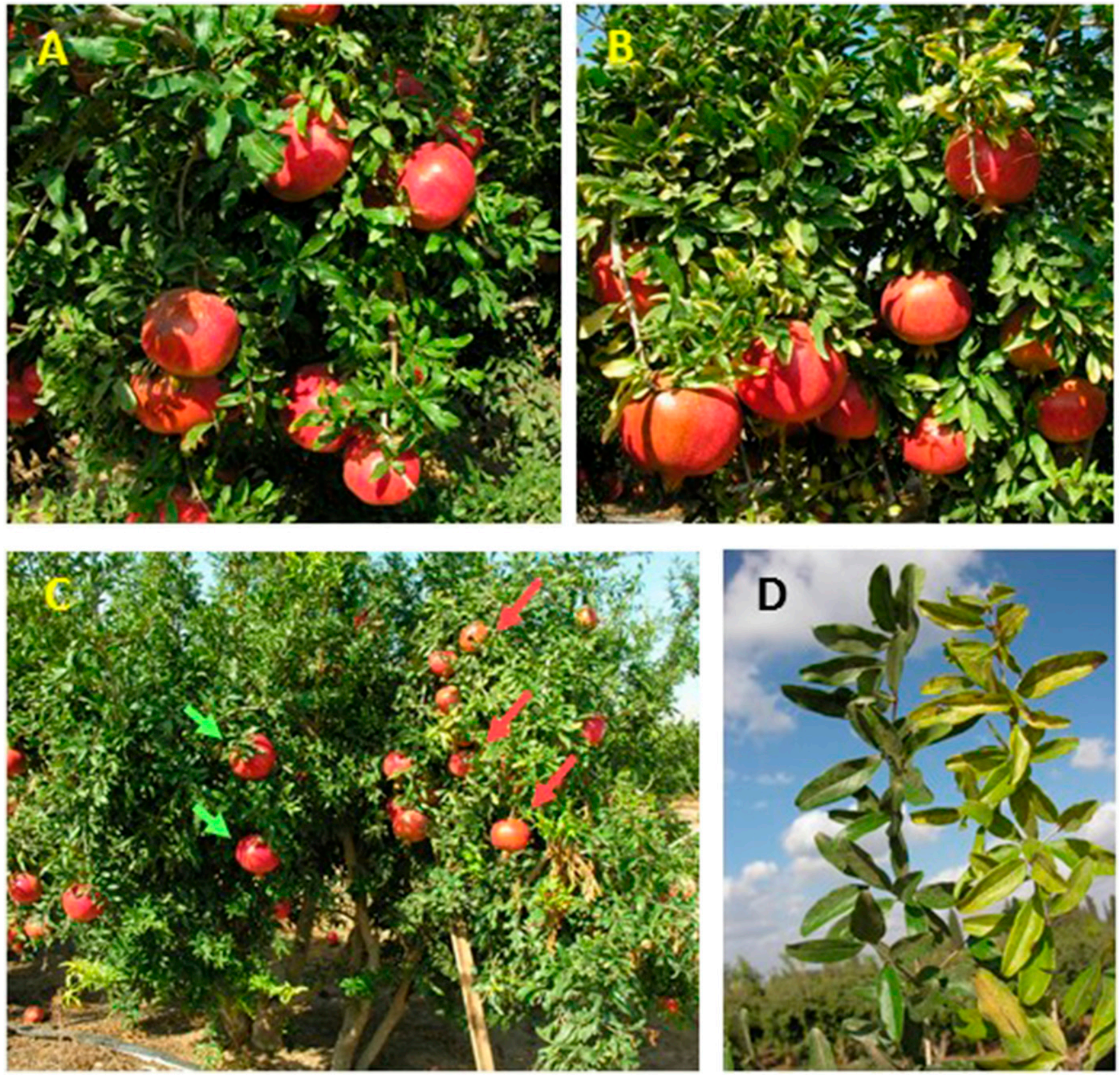

Fig. 1. Photos of pomegranate trees, individual trunks, and branches (cv. Wonderful), growing in a commercial orchard in Kidron, that differ in their visual appearance. Trees (or individual trunks) with dense canopy bearing large, dark-green, glossy leaves were regarded as physiologically resistant to Alternaria alternata; fruits developing on these trees (or trunks) were regarded as physiologically resistant to heart rot (A; $\mathbf{C}$ - green arrows). Trees (or individual trunks) with transparent canopy bearing small, light-green, dull leaves were regarded as physiologically susceptible to $A$. alternata; fruits developing on these trees (or trunks) were regarded as physiologically susceptible to heart rot (B; C - red arrows). (D) Annual shoots that were cut from these trees: the shoot from a resistant individual trunk is on the left and that from a susceptible individual trunk is on the right. 
The relationship between the visual appearance of pomegranate trees and individual trunks and their vulnerability to heart rot. The genotypic characteristics of trees growing in commercial orchards and of individual trunks growing on any given tree are identical. In an effort to keep trees and fruit homogeneous, all trees of the same orchard are usually purchased from the same nursery, propagated by cuttings from the same mother plant (personal knowledge and Rajan and Markose 2007); therefore it was hypothesized that robust and frail trees or individual trunks, and the fruits developing on them, differ in their physiological responses to the pathogen rather than due to differences in factors such as genetic background or source of plants. In that regard, the robust trees have been considered to be "physiologically resistant" to A. alternata and the frail ones "physiologically susceptible" to it.

The incidence of heart-rot-symptomatic fruits developing on apparently physiologically resistant and physiologically susceptible trees and individual trunks was determined in four commercial orchards of pomegranate cv. Wonderful. Three orchards were in the inner plains of Israel, at Kidron (centered at N 31 $49^{\prime} 08.31$, E $34^{\circ} 48^{\prime} 40.29$ ) and up to $1 \mathrm{~km}$ apart; the fourth orchard was in the northern Negev at Moshvei HaNegev (location N 31 ${ }^{\circ} 20^{\prime} 08.04$, E $34^{\circ} 40^{\prime} 46.51$ ). In the first week of October 2014, just before commercial harvesting began, 12 to 22 trees were selected in each orchard, based on their visual appearance. The selected trees in each orchard were in the same row, a few meters apart; half of the trees or trunks matched the above characterization as physiologically resistant to A. alternata, and the others appeared physiologically susceptible. One branch in each tree was arbitrarily chosen, and the fruits developing on it were counted; the number of fruits per branch ranged from 7 to 32 . Then, for each branch, the number of heart-rot symptomatic fruits was recorded. Identification of symptomatic fruits was done initially by looking for symptoms presented by diseased fruit, such as: discoloration (redness) of one part of the fruit; emission of a hollow sound when knocked, in contrast to the dull sound from healthy fruits; easy release from the tree when picked; light weight; and in some cases a rugged peel. Later, to ensure that we identified all the diseased fruit on the specific branch, all the fruits on that branch were picked and cut open (Ezra et al. 2015). The percentage of such fruits was calculated. Differences between the incidence of heart-rot symptomatic fruits on the robust trees and that on the frail trees (or trunks) in each orchard were subjected to the unpaired two-tails $t$ test $(P<0.05)$.

Factors affecting the response of pomegranate fruit responses to A. alternata. To quantify the differences between physiologically resistant and physiologically susceptible pomegranate fruits, asymptomatic fruits developing on apparently resistant and on apparently susceptible trees (or individual trunks) were examined in 2015. Fruits were collected from three orchards; the first two were in Kidron and in Moshvei HaNegev, in the locations indicated above for 2014, and the third was in the Lachish region (Kiryat Gat; N 31 $36^{\prime} 11.86$, E $\left.34^{\circ} 47^{\prime} 45.26\right)$. In the second week of October 2015, just before commercial harvesting, 10 trees were selected in each orchard, based on their visual appearance. In each orchard, the selected trees were in the same row, a few meters apart. Visually, half of the trees (or individual trunks) appeared (as indicated above) to be physiologically resistant and the others to be physiologically susceptible to A. alternata. Five asymptomatic fruits were sampled from each tree (or individual trunk). The aim was to harvest fruits with comparable properties with respect to their location in the tree, size, color, and maturity. The fruits were brought to the laboratory and stored at $4{ }^{\circ} \mathrm{C}$ pending processing. For each treatment (i.e., orchard $\times$ tree response), two fruits were surface sterilized by dipping in $1 \%$ hypochlorite for $3 \mathrm{~min}$, washed twice with distilled water, dried in a sterile laminar air flow, and peeled. Arils from these fruits were squeezed through sterile cheesecloth into a sterile 50-ml vial, and the juice from both fruits was mixed and stored at $4{ }^{\circ} \mathrm{C}$ pending use. The germination of A. alternata spores in the juice was determined as described below, and the acidity level $(\mathrm{pH})$ and sugar content $\left({ }^{\circ} \mathrm{Brix}\right)$ of the juice were determined, respectively, with an Accumet AP 61 pH meter (Fisher Scientific, Pittsburgh, USA) fitted with an Accumet AP 50 glass probe (Fisher Scientific), and a pr-1 digital refractometer (Atago, Tokyo, Japan).

A. alternata isolate POMintrot-94, isolated from the black rot of a diseased fruit from Kidron (Ezra et al. 2015), was used for the fungal spore germination experiments. A piece of mycelium from a fresh culture of the fungus was transferred onto potato dextrose agar (PDA) plates and incubated for at least 1 week before spores were harvested. Five milliliters of sterile $\mathrm{ddH}_{2} \mathrm{O}$ were added to each plate, a sterile ear swab was used to scrape the mycelium, and the resulting suspension was collected with a pipetor and filtered through two layers of sterile cheesecloth. The filtered spore suspension was examined under a microscope to confirm the presence of spores.

A $10-\mu l$ drop of spore suspension, containing $3 \times 10^{5}$ spores $/ \mathrm{ml}$, was added to a $10-\mu l$ drop of pomegranate juice on a microscope slide, and slides were placed on wet permeable paper in closed petri dishes, to maintain high humidity at $25^{\circ} \mathrm{C}$ for $6.5 \mathrm{~h}$. Preliminary experiments revealed that $>95 \%$ of the viable A. alternata spores had germinated during that time. Then, a $10-\mu l$ drop of cotton blue was added to the suspension, to stop spore germination and germ-tube elongation. Spore germination in water was used as a control. On the next day, the percentage of spore-germination was determined by examination through a microscope at $\times 100$ magnification; a spore was regarded as germinating if the germ tube was longer than the width of the spore. Thirty spores were inspected and counted for each treatment, and the spore-germination percentage was calculated. The tests were repeated with the other two fruits that had been maintained in cold storage. Results of the two tests were pooled and the average values $( \pm \mathrm{SE})$ of spore germination, juice acidity, and sugar content were determined for each treatment in each of the orchards.

Fruits also were sampled from the ARO pomegranate collection located in Newe Ya'ar, in the Yizra'el Valley (N 32 $43^{\prime} 02.83$, E $35^{\circ} 11^{\prime} 09.00$ ). The collection encompasses a core of $110 P$. granatum accessions collected from Israel and from various geographical regions worldwide; it includes local and foreign commercial cultivars, land races, locally bred cultivars, and various accessions that display interesting traits. This collection was phenotyped and genotyped as described by Ophir et al. (2014) and Holland et al. (2009). Fruits were collected from 95 accessions in 2015 and from 110 accessions in 2016. Because the maturation characteristics of the accessions differed markedly, harvesting was performed three times in 2015 (August 15, September 9, and October 19) and five times in 2016 (August 8, September 11, October 9 and 27, and November 7). On each harvesting date, five mature fruits of the relevant accessions were collected, brought to the laboratory, and maintained and processed as described above. Fruits of cv. Wonderful were harvested on all three harvesting dates in 2015 , and on the second, third, and fourth harvesting dates in 2016, to enable documentation of temporal variation in the effects of juice properties on spore germination. Then, the germination rates of A. alternata spores in the juice and the acidity level $(\mathrm{pH})$ and sweetness $\left({ }^{\circ} \mathrm{Brix}\right)$ of the juice were determined. Sigmoidal regression equations were used to quantify the relationships between the juice acidity $(\mathrm{pH})$ or its sugar content ( $\left.{ }^{\circ} \mathrm{Brix}\right)$, as the independent variables, and spore germination percentage as the dependent variable using SigmaPlot software (SPSS Inc.). Analyses were performed separately for the 2015 and 2016 data sets.

It is reasonable to assume that the acidity of the solution affects the germination of fungal spores; therefore it is possible that the acidity of the pomegranate juice directly affected the germination of A. alternata spores. However, it also is possible that effects on spore germination are indirect. For example, it could be that the juice acidity alters the activity of a compound(s) present in the juice, and that they, in turn, inhibit spore germination. To distinguish between these two possibilities, we examined the germination of A. alternata spores in two sets of solutions, each with a range of acidity levels. The first was pomegranate juice prepared from fruits of $\mathrm{cv}$. Wonderful; the other was a water solution. The water solutions were prepared by addition of hypochloric acid $(\mathrm{HCl})$ or sodium hydroxide $(\mathrm{NaOH})$ to sterile $\mathrm{ddH}_{2} \mathrm{O}$ until the desired $\mathrm{pH}$ value was obtained. For the water test, $1 \mathrm{ml}$ of spore suspension, containing $3 \times 10^{5}$ spores $/ \mathrm{ml}$, in a $1.5-\mathrm{ml}$ Eppendorf tube, was centrifuged at $17,000 \times g$ at room temperature 
for $1 \mathrm{~min}$. The supernatant was discarded and $1 \mathrm{ml}$ of the test solution, having $\mathrm{pH}$ in the range of 2 to 5 , was added to the spore pellet. Spores were resuspended by vortexing for $20 \mathrm{~s}$, and $10 \mu \mathrm{l}$ of the suspension was placed on a microscope slide and covered with a cover glass. Spore germination in the solutions was determined as described above. The experiment was repeated three times and the results were pooled. A sigmoidal regression equation (with three parameters) was used to quantify the relationship between solution acidity (the independent variable) and spore germination rate (the dependent variable). To test whether germination of $A$. alternata spores in the juice had altered its acidity, a series of pomegranate juices with $\mathrm{pH}$ ranging from 2 to 4 was prepared as described above. A 1-ml sample of juice was poured into an Eppendorf tube and its acidity was determined. Then, $100 \mu \mathrm{l}$ of spore suspension was added to each tube. The test comprised five acidity levels (treatments) with four Eppendorf tubes (repetitions) per treatment. The tubes were maintained at $25^{\circ} \mathrm{C}$ for $6.5 \mathrm{~h}$, and the juice acidity level was recorded once again. This test was repeated once.

\section{Results}

The relationship between the visual appearance of pomegranate trees and individual trunks, and their susceptibility to heart rot. The number of pomegranate fruits developing on the apparently resistant trees (or individual trunks) did not differ significantly from the number developing on the apparently susceptible ones. In the three orchards in Kidron, the numbers of fruits developing on branches of resistant trees $( \pm \mathrm{SE})$ were $19.4 \pm 2.5,14.3 \pm 1.7$, and $16.2 \pm 1.3$; in Moshvei HaNegev it was $9.2 \pm 0.8$. The corresponding numbers of fruits developing on branches of susceptible trees in the same four orchards were $16.3 \pm 2.4,12.7 \pm 4.5,17.2 \pm 3.8$, and $9.0 \pm 1.2$, respectively. However, there was a significant difference between apparently susceptible and apparently resistant branches, in the incidence of heart-rot-symptomatic fruits: while 8.4-40.6\% of the fruits on the susceptible branches were symptomatic, only $0-3.4 \%$ of those on the resistant branches exhibited heart-rot symptoms (Fig. 2).

Factors affecting the response of pomegranate fruit responses to $A$. alternata. The spore germination rate in pomegranate juice was significantly influenced by the characteristics of the fruits from which the juice was prepared. A significantly lower germination rate $(P=0.02)$ was observed in juice from asymptomatic fruits grown on physiologically resistant trees $(21.8 \%)$ than in juice from asymptomatic fruits from physiologically susceptible ones $(38.1 \%)$ The results, presented in Figure 3A, B, and C, are an average of three experiments. Comparable differences were observed between the acidity levels of the respective juices (Fig. 3D, E, and F), but not between their sugar contents (Fig. 3G, H, and I).

When immature Wonderful fruits were harvested, the $\mathrm{pH}$ of their juice was below 3.5; the germination of A. alternata spores in these juices also was low. However, when mature fruits were harvested, the higher $\mathrm{pH}(>3.7)$ of the juice was associated with a greater percentage of germinating spores (Fig. 4).

Germination of A. alternata spores was significantly affected by the acidity level of the medium (water or pomegranate juice). Spores did not germinate at $\mathrm{pH}<2.5$, whereas all viable spores germinated at $\mathrm{pH}>4.3$. However, within the $\mathrm{pH}$ range of 2.5 to 4.3 , there were marked differences in spore germination rates between the water and the pomegranate juice solutions: germination was initiated at $\mathrm{pH} 2.75$ in the water solution and at 3.75 in the juice solution; all viable spores germinated at $\mathrm{pH} 3.25$ in the water and at 4.25 in the pomegranate juice solutions (Fig. 5). The germination of A. alternata spores in the pomegranate juice was only minimally affected by juice acidity after $6.5 \mathrm{~h}$ of incubation (results not shown).

In both years of the study, there was a wide range of spore germination rates in the juices of fruits sampled from the various accessions of the Newe Ya'ar collection. While most $(>80 \%)$ of the spores germinated in some of the juices, there were other juices in which very few $(<3 \%)$ did so; variation in the trait of spore germination was continuous. Spore germination rate in juice prepared from fruits of cv. Wonderful varied irregularly: $41.8 \%$ in 2015 and $40.8 \%$ in 2016 (Fig. 6). A significant $(P<0.0001)$ sigmoidal relationship — with three parameters - was observed between juice acidity and spore germination rate in both years. Few spores $(<5 \%)$ germinated at $\mathrm{pH}<3.2$; germination rates increased with increasing $\mathrm{pH}$, and in juices at $\mathrm{pH}>3.8,50 \%$ of the spores had germinated (Fig. 7A, C). No obvious correspondence was observed between the sugar content of the juice and spore germination rate; in both years (Fig. 7B, D), attempts to compute linear or nonlinear regression equations for the data yielded nonsignificant $(P>0.3)$ results.

\section{Discussion}

The etiology and development of heart rot disease of pomegranate has many similarities with those of core rot in Red Delicious apples. First, the same fungus, A. alternata, is the pathogen causing the disease in both crops (Ezra et al. 2015; Niem et al. 2007; Reuveni et al.
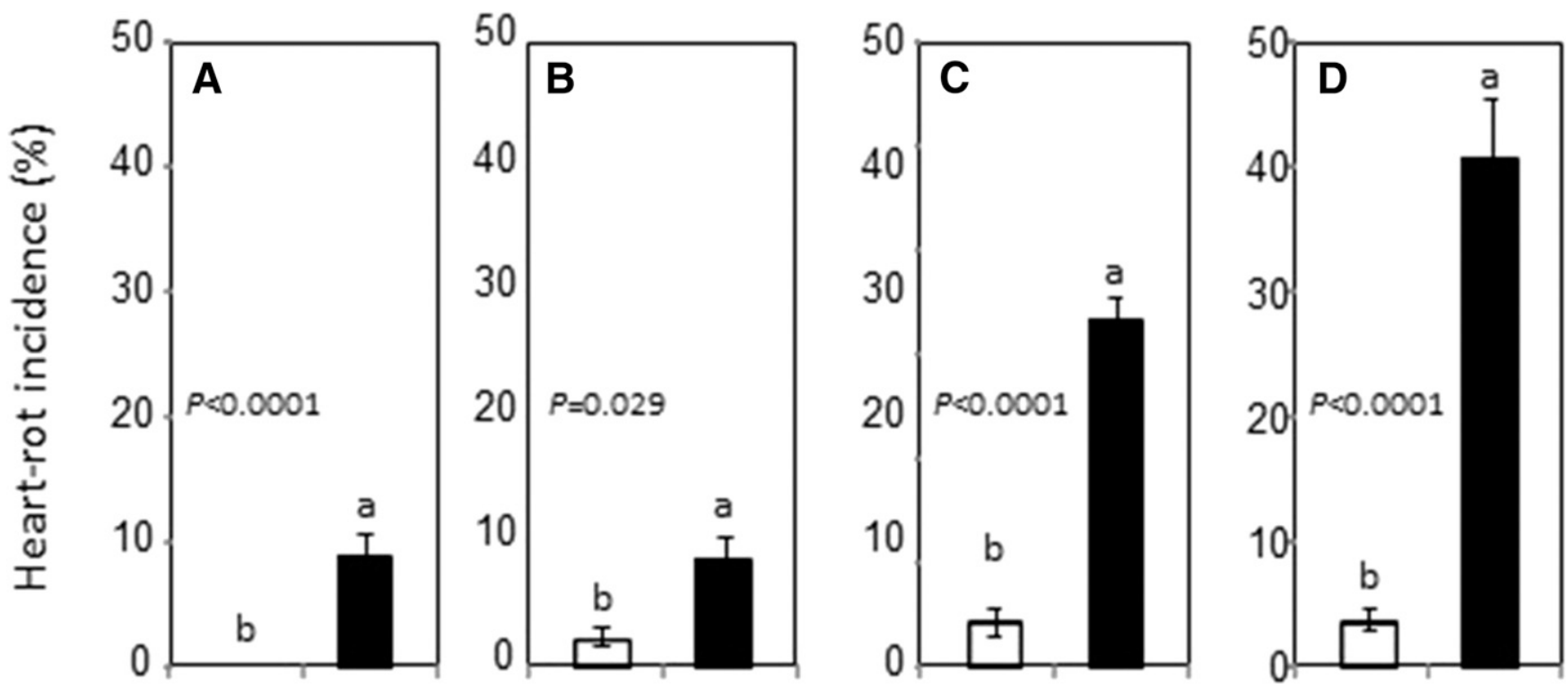

Fig. 2. Development of heart-rot-symptomatic pomegranate fruits (cv. Wonderful) growing on physiologically resistant (open bars) and physiologically susceptible (filled bars) trees or trunks in commercial orchards in Kidron (A, B, C) and Moshvei HaNegev (D). The fruits were collected just before commercial harvest in 2014. Individual branch response was determined based on the visual tree's (or individual trunk's) appearance as explained in the text. In each panel, values of bars marked with different letters differ significantly (as determined by unpaired, two-tails $t$ test) at the indicated probability. The vertical bars represent the standard error of the mean. 
2002; Tziros et al. 2008; Zhang and McCarthy 2012). There are at least seven pathogenic variants of specific A. alternata forma specialis (or pathotypes), each producing unique host-selective toxins (HSTs), and causing disease on specific host plants (Hatta et al.
2002; Ito et al. 2004; Kohmoto et al. 1991). It is possible that heart rot and core rot are caused by a unique pathotype of A. alternata, but there is no empirical evidence for or against this hypothesis. We are currently studying this possibility by molecular methods
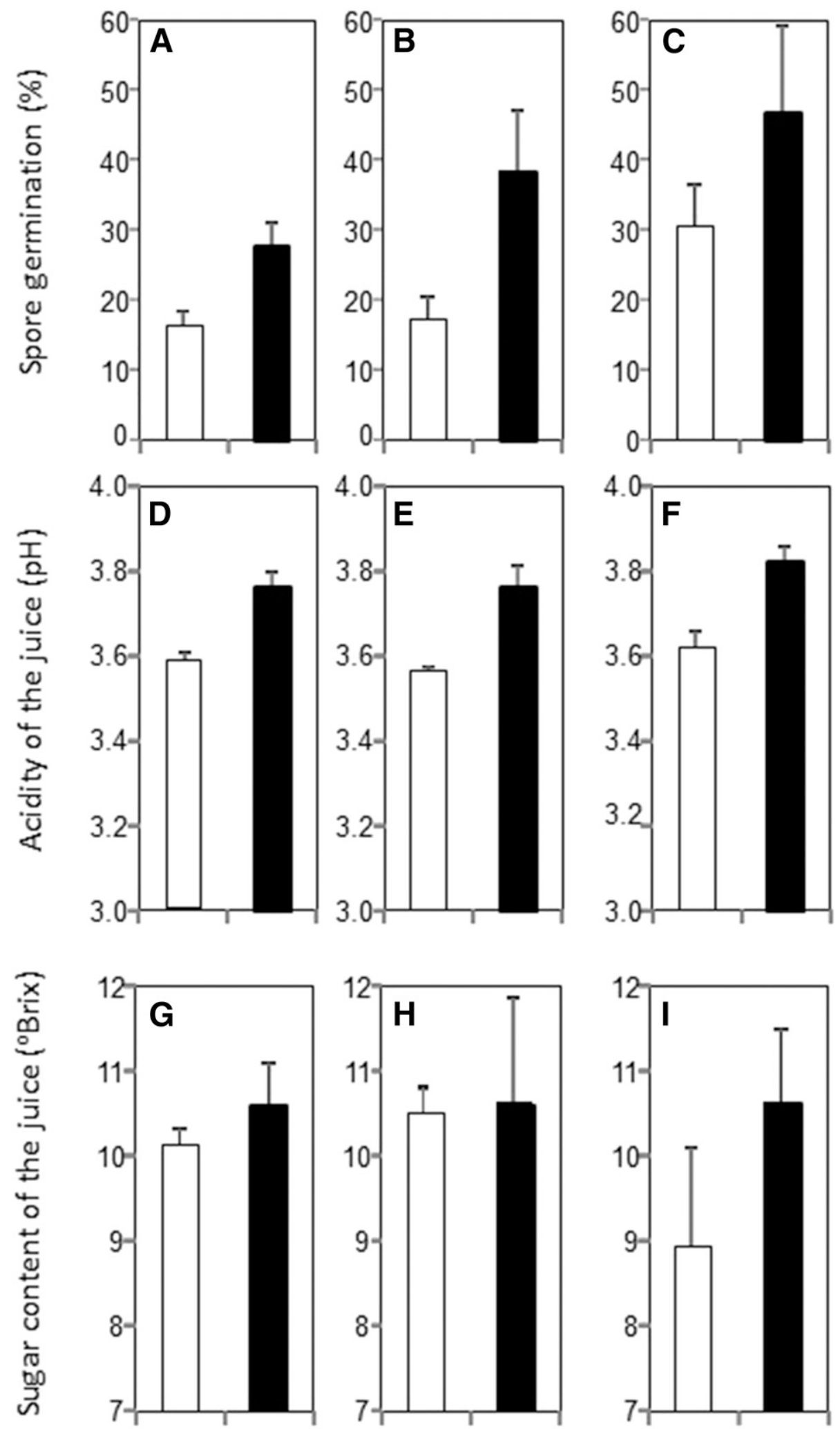

Fig. 3. Germination of Alternaria alternata spores in juice from asymptomatic pomegranate fruits, cv. Wonderful (A, B, C); acidity level of the juice (D, E, F); and sweetness of the juice (G, H, I). Asymptomatic fruits were sampled from physiologically resistant (open bars) and physiologically susceptible (filled bars) branches of trees (or trunks) growing in three commercial orchards: Lakhish (A, D, G), Kidron (B, E, H), and Moshvei HaNegev (C, F, I). The fruits were collected just before commercial harvest in 2015. Branch responses were determined from their visual appearance as explained in the text. The vertical bars represent the standard error of the mean. 


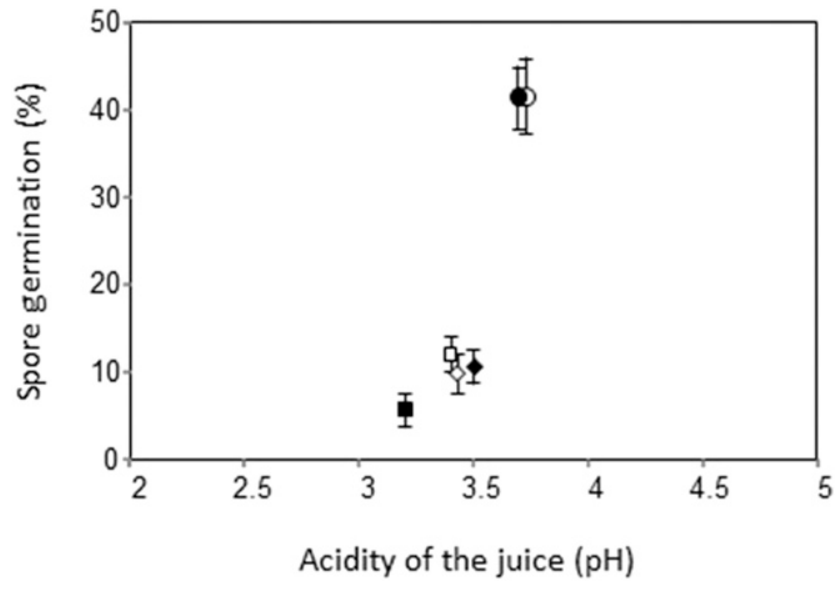

Fig. 4. Relationship between the acidity of pomegranate juice (cv. Wonderful) and the germination rate of Alternaria alternata spores in the juice. The fruits were harvested from the Newe Ya'ar collection on August 15, September 9, and October 19, 2015 (open square, diamond, and circle, respectively) and September 11 and October 9 and 27, 2016 (filled square, diamond, and circle, respectively).

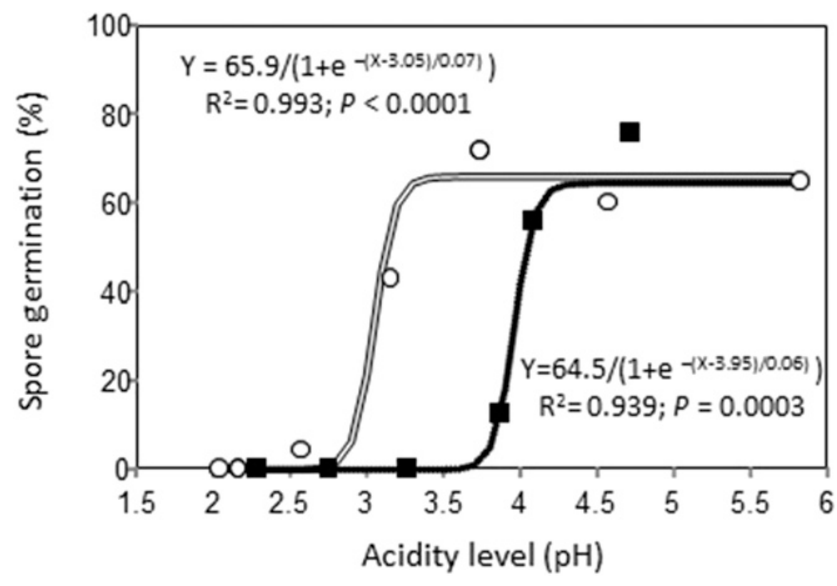

Fig. 5. Relationship between the acidity levels $(\mathrm{pH})$ of water (open circles) or pomegranate juice (cv. Wonderful; filled squares) solutions and germination rate of Alternaria alternata spores. for Alternaria isolates from pomegranate heart rot. We intend to infect several host plants with different fungal strains for determining the existence of forma specialis and/or pathotypes among these strains. Because the pathogen, A. alternata, is capable of developing saprophytically and sporulates abundantly on senescing tissues and organic matter in the orchard (Rotem 1994), development of fruit infection presumably is not limited by lack of susceptible host tissue or of virulent pathogens.

Second, in both diseases, the pathogen infects open flowers, colonizes the pistil, and subsequently develops through the tunnel connecting the pistil to the loculi (in pomegranate), or through the calycine tube (in apple) that leads to the receptacle (the core region of apple fruits). The pathogen remains latent until fruit maturity, when it resumes its development and causes disease symptoms (De Kock et al. 1991; Ezra et al. 2015; Niem et al. 2007; Spotts 1990; Spotts et al. 1988).

The development of plant diseases is commonly governed by the suitability of environmental conditions to the pathogen. In a previous study, it was demonstrated that in Israel the environmental conditions prevailing during bloom did not limit $A$. alternata colonization of apple pistils and the development of moldy core or core rot in apple fruits (Shtienberg 2012). Although these effects have not been studied for the heart-rot/pomegranate pathosystem, several lines of evidence may indicate that the environmental conditions prevailing during bloom in Israel do not limit A. alternata colonization of pomegranate pistils and heart rot development in pomegranate fruits. The pathogen was isolated from the pistils of more than $80 \%$ of the fruits sampled from orchards located in distinct production areas, over several years, and at all fruit development stages from flower opening to ripeness (Ezra et al. 2015). Furthermore, in the present study it was demonstrated that there were large differences in heart-rot incidence among trees growing side by side in an orchard (Fig. 2). The distribution of trees bearing fruits with heart rot in the orchard precludes the possibility that environmental conditions affect heart rot development: temperature, humidity, rainfall, and their interactions do not differ markedly over such small distances. These observations may indicate that factors other than the presence of the pathogen or the prevailing environmental conditions govern the development of heartrot symptoms in pomegranate orchards in Israel. Accordingly, we hypothesized that heart-rot incidence in individual orchards is governed by host physiology; a similar hypothesis was proposed for core-rot development in Red Delicious apples (Shtienberg 2012).

Heart rot and core rot symptoms in pomegranate and Red Delicious apples develop internally. Trained individuals may identify symptomatic fruits with appreciable success: visually, based on their color, which is slightly darker than that of nearby asymptomatic
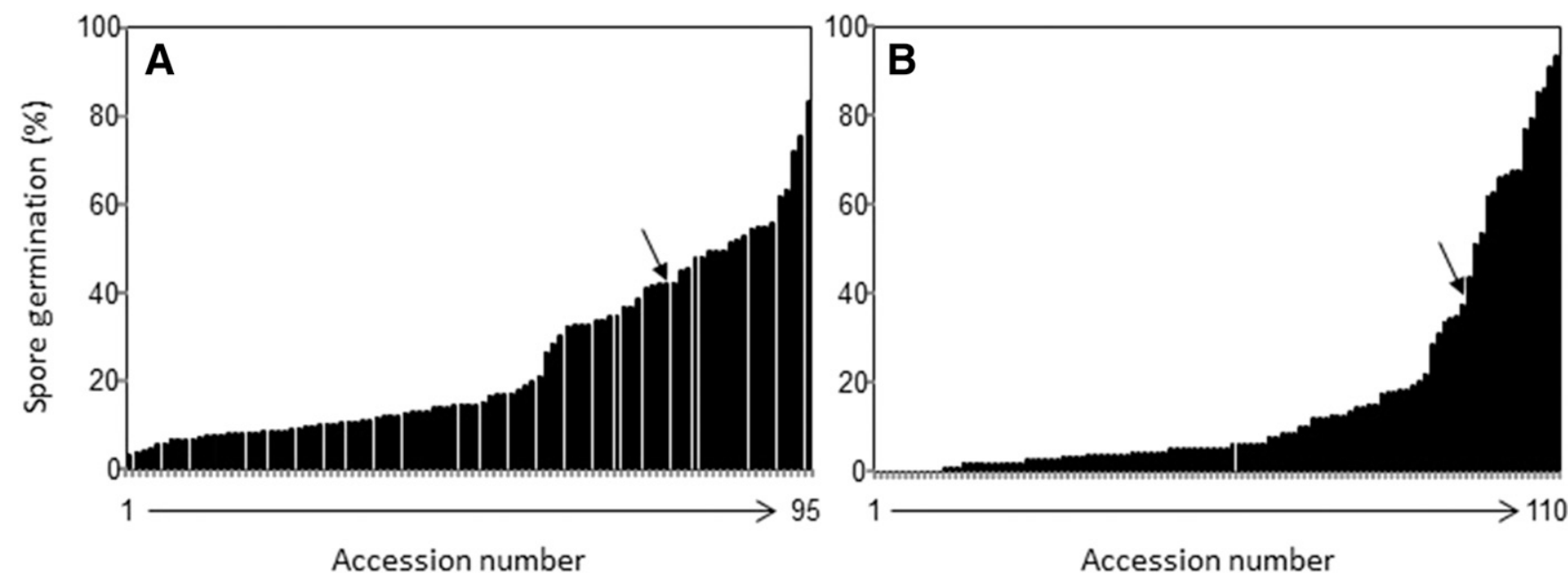

Accession number

Fig. 6. Varied responses of pomegranate accessions to Alternaria alternata. Fungal spores were added to juice made from asymptomatic fruits sampled from 95 cultivars/lines growing in the ARO collection in Newe Ya'ar in 2015 (A) and 2016 (B), and spore germination rates were determined after $6.5 \mathrm{~h}$. Accessions were ordered according to their responses, from the most resistant (no. 1) to the most susceptible (nos. 95 or 110). The arrows point to cv. Wonderful. 
fruits; shape, which is more angular than that of asymptomatic fruits; and according to the sound produced by tapping on the fruits with a finger, which is more hollow in symptomatic than in asymptomatic fruits. Untrained individuals rarely identify symptomatic fruits. Studying the etiology and epidemiology of these diseases requires accurate identification of symptomatic fruits, which can be achieved only by cutting the sampled fruits and observing the lower loculus (pomegranate) or inner flesh (apple). For that reason, during his 4year study, Shtienberg (2012) harvested, cut, inspected, and scored more than 35,000 apple fruits. In light of the high cost of pomegranate fruits, it was not feasible to cut the large number of fruits needed for testing the hypothesis that heart rot incidence is governed by host physiology, in a study based on the existence of symptomatic fruits. Thus, there was a need to develop an easy, reliable, and repeatable test based on the response of asymptomatic pomegranate fruits, and two slightly different bioassays were developed for this purpose. The first entailed quantifying the germination rate of $A$. alternata spores in juice produced from one or more pomegranate fruit(s) described herein and in Ezra et al. (2017). The second bioassay encompasses both germination of spores and development of A. alternata mycelia (results not shown). The two bioassays were conducted concurrently and yielded comparable results. After considering the advantages and weaknesses of the two respective bioassays, it was decided to use the former in subsequent experiments; it was found to be easier and faster, and to produce more consistent results than the latter (Ezra et al. 2017). Use of this bioassay enabled sampling of asymptomatic fruits and quantification of their responses to A. alternata.

The present findings supported previous observations that the incidence of heart rot in mature fruits originating from frail pomegranate trees or individual trunks was higher than in fruits originating on robust trees (or individual trunks), growing side-by-side in the same orchard (Fig. 2). Germination of A. alternata spores in juice produced from asymptomatic fruits from the apparently susceptible trees was higher than that of spores in juice from the apparently resistant trees (Fig. 3 ). Thus, the visual appearance of the trees could be used as an indicator of their susceptibility. Because these response differences were recorded in individual, well-defined cultivars, they reflected physiological rather than genetic influences. Nevertheless, the distinct visual differences between the physiologically resistant and the physiologically susceptible trees do not indicate the mode of resistance; recently it was demonstrated that yield load could be used as an indicator for the core-rot susceptibility of Red Delicious apple trees: core-rot incidence in light-cropping trees was higher than in heavy-cropping trees. The former trees were regarded as physiologically susceptible and the latter as physiologically resistant to the disease (Shtienberg 2012).

Next, attempts were made to empirically characterize the juice produced from mature fruits originating from physiologically resistant and physiologically susceptible trees. There were no differences between the sugar contents of these juices (Fig. 3G, H, I), but their acidity levels differed: the $\mathrm{pH}$ of juices derived from the physiologically resistant trees was significantly lower than that of juices from the physiologically susceptible ones. Differences in $\mathrm{pH}$ between the two groups paralleled the spore germination rates in these juices (Fig. 3A to F). The acidity level of pomegranate juice changes over time, as the fruits mature (Fawole and Opara 2013a, b; Holland et al. 2009; Khodabakhshian et al. 2017), and the germination rate of A. alternata spores in the juice changes accordingly (Fig. 4). These observations are consistent with the fact that heart-rot symptoms are rarely seen in unripe pomegranate fruits; they are apparent only
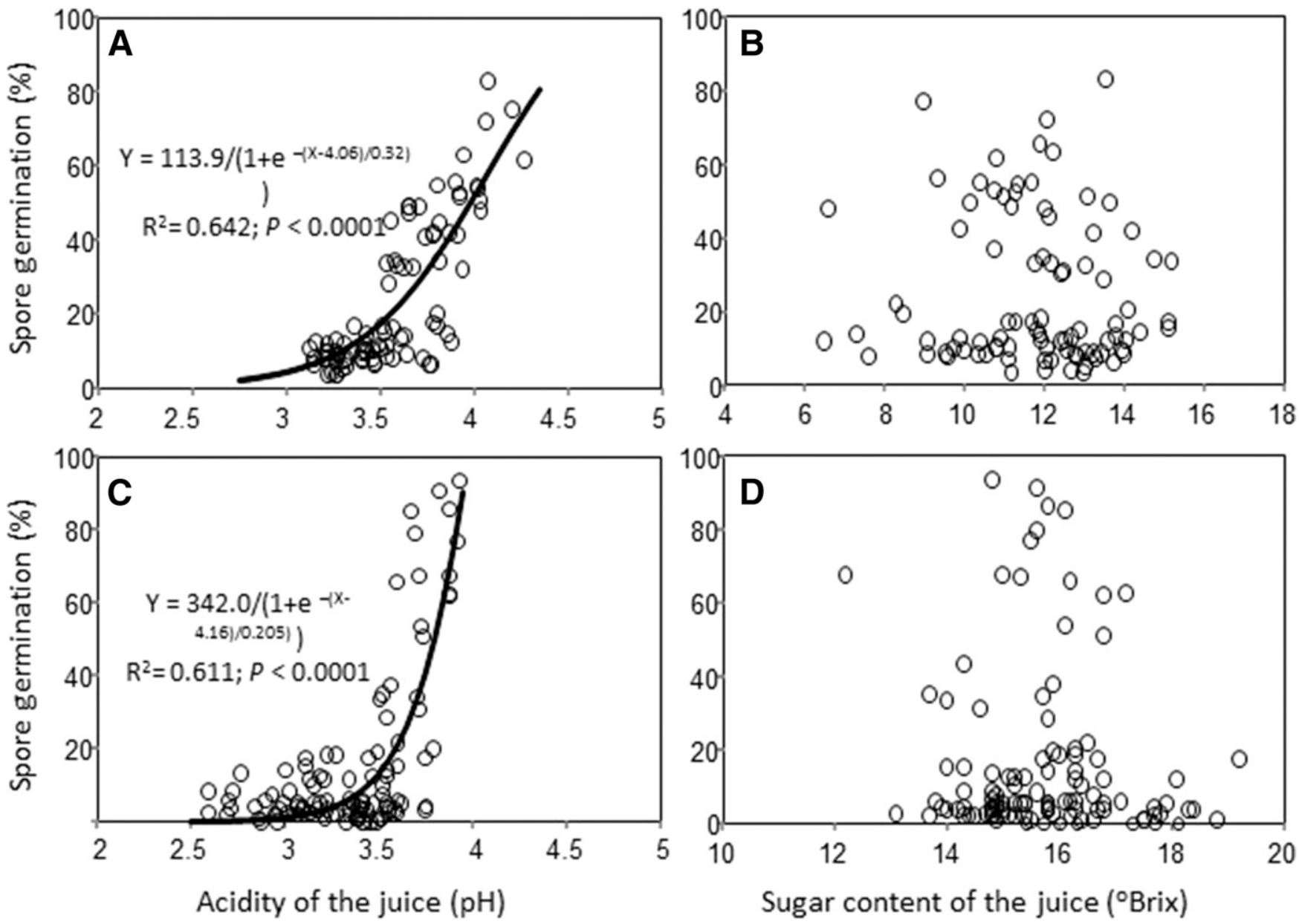

Fig. 7. Effects of acidity level or sugar content of pomegranate juice on the germination rate of Alternaria alternata spores in the juice. The juice was prepared from 95 cultivars/lines growing in the ARO collection in Newe Ya'ar in 2015 (A and B) and 2016 (C and D). 
in mature fruits (Day and Wilkins 2011; Ezra et al. 2015; Tziros et al. 2008; Zhang and McCarthy 2012).

It is well documented that the acidity levels of plant organs govern the infectivity, virulence, and aggressiveness of fungal pathogens colonizing them (Alkan et al. 2013; Cameldi et al. 2017; Fernandes et al. 2017). Moreover, fungal pathogens actively may modify the ambient $\mathrm{pH}$ of the organs they inhabited, to favor their invasion (Bi et al. 2016; Prusky and Yakoby 2003; Prusky et al. 2001; Vylkova 2017). Thus, it was expected that $A$. alternata spores would not germinate in solutions with $\mathrm{pH}$ below a certain threshold level and that all viable spores would germinate when placed in solutions with $\mathrm{pH}$ above a certain threshold level. Indeed, this was observed in our present experiments (Fig. 4). It could be argued that fruits originating from frail or from robust trees would differ in their maturity levels, and that these differences affected the $\mathrm{pH}$ of the juices from these fruits. If this were true, the differences in germination rates of A. alternata spores in juices produced from fruits originated from frail or from robust trees would reflect the maturity of the fruits rather than indicating differences between the resistance capability of the trees. However, our present results support the hypothesis that the acidity level of the juice may be used as an indicator of a tree's response to A. alternata. We have reached this conclusion because there was a marked difference in spore germination rate between the water and the pomegranate juice solutions: at $\mathrm{pH} 3.5$ all viable A. alternata spores $(65.9 \%)$ had germinated in the water solution but none (0\%) did so in the pomegranate juice (Fig. 5). This finding supports the hypothesis that, apart from $\mathrm{pH}$, a compound(s) present in the pomegranate juice regulates the germination of A. alternata spores.

The hypothesis that, apart from $\mathrm{pH}$, a compound(s) present in pomegranate juice regulates the germination of $A$. alternata spores in the juice is further supported by the observations carried out while analyzing the responses of various pomegranate accessions from the Newe Ya'ar collection. Similarly to the results presented in Figures 4 and 5 , the germination rate of A. alternata spores was significantly related to the $\mathrm{pH}$ of the juice. However, at $\mathrm{pH} 3.7$ there was a wide range of spore germination rates among the accessions: in 2015 it ranged from 5 to $55 \%$ and in 2016 from 3 to $92 \%$ (Fig. 7A and C). Obviously, these differences did not reflect the effect of $\mathrm{pH}$; they may have arisen from differences in compound(s) present in the pomegranate juice. As indicated above, these differences may reflect variation in physiological factors affecting the resistance of the trees; alternatively, they may reflect inherent differences between the pomegranate accessions. If the latter interpretation is valid, it indicates that this range of variation reflects genetic variation in the $A$. alternata-resistance response of the pomegranate accessions; such genetically variable response was demonstrated in the A. alternata/ apple pathosystem by Niem et al. (2007), who reported that Red Delicious was susceptible, whereas Golden Delicious was resistant to core-rot development.

The mode of physiological action and the influence of genetic background, if any, on the responses of pomegranate trees to A. alternata is not known. As indicated above, the $\mathrm{pH}$ of the juice produced from mature fruits may be viewed as an indicator for heart-rot response. The acidity of the juice is probably not the only determinant of host resistance; it could be that a certain compound(s) present in the juice inhibit(s) A. alternata. The concentration of such compounds may differ between fruits originating from frail compared with robust trees and thereby affect the physiological resistance responses, and between trees of differing accessions, thereby determining the genetic resistance responses. The antifungal activity of such compound(s) might be governed by the acidity level of the juice, thereby resulting in the response curves presented in Figures 4 and 7. Indeed, it was recently reported that pomegranate juice and peel contain a range of antioxidant polyphenol compounds, such as punicalagin, which exhibit significant antimicrobial activity (BetanzosCabrera et al. 2015; Foss et al. 2014; Tehranifar et al. 2011).

Elucidating the mode of resistance and the compound(s) involved is of great importance for developing means to enhance the physiological resistance against heart rot of a widely grown commercial cultivar. It may be that a few minor modifications of commonly used agronomical practices such as fertilization would increase the content of the relevant compound(s) in the fruits, or modify the acidity of their juice to increase their antifungal activity. Mineral nutrition can exert a profound effect on disease development; fertilizer application can enhance or mitigate development of diseases caused by various pathogens. The mechanisms leading to these nutrient-induced changes in disease development are complex and numerous: they include direct effects of mineral nutrients on the pathogen, on plant growth and development, and on plant resistance mechanisms (Walters and Bingham 2007). For example, calcium was mentioned as one of the elements whose content in the locule wall might be related to apple fruit susceptibility to core rot (Shtienberg 2012). Calcium polygalacturonates are required in the middle lamella for cellwall stability, and A. alternata, like many other parasitic fungi, invades plant tissues by producing extracellular pectolytic enzymes such as polygalacturonase, which dissolve the middle lamella (Niem et al. 2007). The activity of these enzymes is drastically inhibited by calcium (Elad and Evensen 1995; Taiz and Zeiger 2002). This knowledge had stimulated A. Levin, U. Yermiyahu, and D. Shtienberg (unpublished) to search for means to enhance calcium content in the locule wall of Red Delicious apples.

Elucidating the mode of resistance and the compound(s) involved is of great importance for breeding new cultivars with enhanced genetic resistance against heart rot. The intensifying demands to reduce the use of pesticides in agriculture motivate breeders to search for lines resistant to plant diseases, in parallel with their attempts to improve the agronomic characteristics of the cultivars. Finding genetic markers for susceptibility or resistance to the pathogen could be helpful in testing the responses of trees that are already growing in commercial orchards: to predict their vulnerability to the disease; to preselect resistant progenies that already are in the nursery stage in breeding programs; and to gain better understanding of the physiology and nature of the disease.

\section{Acknowledgments}

The authors wish to thank Mr. Yuval Ben Israel for letting us use his orchards for these experiments.

\section{Literature Cited}

Alkan, N., Espeso, E. A., and Prusky, D. 2013. Virulence regulation of phytopathogenic fungi by pH. Antioxid. Redox Signal. 19:1012-1025.

Betanzos-Cabrera, G., Montes-Rubio, P. Y., Fabela-Illescas, H. E., BelefantMiller, H., and Cancino-Diaz, J. C. 2015. Antibacterial activity of fresh pomegranate juice against clinical strains of Staphylococcus epidermidis. Food Nutr. Res. 59:1-9.

Bi, F., Barad, S., Ment, D., Luria, N., Dubey, A., Casado, V., Glam, N., Diaz Minguez, J., Espeso, E. A., Fluhr, R., and Prusky, D. 2016. Carbon regulation of environmental $\mathrm{pH}$ by secreted small molecules that modulate pathogenicity in phytopathogenic fungi. Mol. Plant Pathol. 17:1178-1195.

Cameldi, I., Neri, F., Menghini, M., Pirondi, A., Nanni, I. M., Collina, M.,and Mari, M. 2017. Characterization of Neofabraea vagabunda isolates causing apple bull's eye rot in Italy (Emilia-Romagna region). Plant Pathol. 66: $1432-1444$

Day, K. R., and Wilkins, E. D. 2011. Commercial pomegranate (Punica granatum L.) production in California. Acta Hortic. 890:275-285.

De Kock, S. L., Visagie, T. R., and Combrink, J. C. 1991. Control of core rot in Starking apples. Decid. Fruit Grow. 41:20-22.

Elad, Y., and Evensen, K. 1995. Physiological aspects of resistance to Botrytis cinerea. Phytopathology 85:637-643.

Ezra, D., Gat, T., Skovorodnikova, Y., Vardi, Y., and Kosto, I. 2010. First report of Alternaria black spot of pomegranate caused by Alternaria alternata in Israel. Australas. Plant Dis. Notes 5:1-2 A.

Ezra, D., Kirshner, B., Hershcovich, M., Shtienberg, D., and Kosto, I. 2015. Heart rot of pomegranate: Disease etiology and the events leading to development of symptoms. Plant Dis. 99:496-501.

Ezra, D., Shulhani, R., and Shteinberg, D. 2017. A method for evaluation of pomegranate fruit sensitivity to Alternaria alternata, the causal agent of black heart disease. Page 91 in: Proc. of the ISHS 4th Internat. Symp. on Pomegranate and Minor Mediterranean Fruits. Elche, Spain.

Fawole, O. A., and Opara, U. L. 2013a. Developmental changes in maturity indices of pomegranate fruit: A descriptive review. Sci. Hortic. (Amsterdam) 159: 152-161.

Fawole, O. A., and Opara, U. L. 2013b. Effects of maturity status on biochemical content, polyphenol composition and antioxidant capacity of pomegranate fruit arils (cv. "Bhagwa"). S. Afr. J. Bot. 85:23-31. 
Fernandes, T. R., Segorbe, D., Prusky, D., and Di Pietro, A. 2017. How alkalinization drives fungal pathogenicity. Cyril Zipfel, ed. PLOS Pathog. 13:e1006621.

Foss, S. R., Nakamura, C. V., Ueda-Nakamura, T., Cortez, D. A., Endo, E. H., and Dias Filho, B. P. 2014. Antifungal activity of pomegranate peel extract and isolated compound punicalagin against dermatophytes. Ann. Clin. Microbiol. Antimicrob. 13:32.

Hatta, R., Ito, K., Hosaki, Y., Tanaka, T., Tanaka, A., Yamamoto, M., Akimatsu, K., and Tsuge, T. 2002. A conditionally dispensable chromosome controls host-specific pathogenicity in the fungal plant pathogen Alternaria alternata. Genetics 161:59-70.

Holland, D., Hatib, K., and Bar-Ya'akov, I. 2009. Pomegranate: Botany, horticulture, breeding. Hortic. Rev. (Am. Soc. Hortic. Sci.) 35:127-191.

Ito, K., Tanaka, T., Hatta, R., Yamamoto, M., Akimitsu, K., and Tsuge, T. 2004. Dissection of the host range of the fungal plant pathogen Alternaria alternata by modification of secondary metabolism. Mol. Microbiol. 52:399-411.

Khodabakhshian, R., Emadi, B., Khojastehpour, M., and Golzarian, M. R. 2017. Determining quality and maturity of pomegranates using multispectral imaging. J. Saudi Soc. Agric. Sci. 16:322-331.

Kohmoto, K., Akimitsu, K., and Otani, H. 1991. Correlation of resistance and susceptibility of citrus to Alternaria alternata with sensitivity to host-specific toxins. Phytopathology 81:719-722.

Levin, G. M. 2006. Pages 15-183 in: Pomegranate Roads: A Soviet Botanist's Exile from Eden. B. L. Baer, ed. Floreat Press, Forestville, CA.

Luo, Y., Hou, L., Förster, H., Pryor, B., and Adaskaveg, J. E. 2017. Identification of Alternaria species causing heart rot of pomegranates in California. Plant Dis. 101:421-427.

Michailides, T., Morgan, M., Quist, M., and Reyes, H. 2008. Infection of pomegranate by Alternaria spp. causing black heart. (Abstr.) Phytopathology 98:S105.

Niem, J., Miyara, I., Ettedgui, Y., Reuveni, M., Flaishman, M., and Prusky, D. 2007. Core rot development in Red Delicious apples is affected by susceptibility of the seed locule to Alternaria alternata colonization. Phytopathology 97:1415-1421.

Ophir, R., Sherman, A., Rubinstein, M., Eshed, M., Schwager, R., Sharabi, M., Harel-Beja, R., Bar-Ya'akov, I., and Holland, D. 2014. Single-nucleotide polymorphism markers from de-novo assembly of the pomegranate transcriptome reveal germplasm genetic diversity. PLoS One 9:e88998.

Pala, H., Tatli, A., Yilmaz, C., and Özgüven, A. I. 2009. Important diseases of pomegranate fruit and control possibilities in Turkey. Acta Hortic. 818:285-290.

Prusky, D., McEvoy, J. L., Leverentz, B., and Conway, W. S. 2001. Local modulation of host $\mathrm{pH}$ by Colletotrichum species as a mechanism to increase virulence. Mol. Plant-Microbe Interact. 14:1105-1113.
Prusky, D., and Yakoby, N. 2003. Pathogenic fungi: Leading or led by ambient pH? Mol. Plant Pathol. 4:509-516.

Rajan, S., and Markose, B. L. 2007. Pages 74-75 in: Propagation of Horticultural Crops, vol. 6. Horticulture Science Series, New India Publishing, New Delhi, India.

Reuveni, M., Sheglov, D., Sheglov, N., Ben-Arie, R., and Prusky, D. 2002. Sensitivity of Red Delicious apple fruit at various phenologic stages to infection by Alternaria alternata and moldy-core control. Eur. J. Plant Pathol. 108:421-427.

Rotem, J. 1994. The Genus Alternaria: Biology, Epidemiology, and Pathogenicity. American Phytopathological Society, St. Paul, MN.

Shtienberg, D. 2012. Effects of host physiology on the development of core rot, caused by Alternaria alternata, in Red Delicious apples. Phytopathology 102:769-778.

Spotts, R. 1990. Moldy core and core rot. Pages 9-10 in: Compendium of Apple and Pear Diseases. H. S. Jones and A. L. Aldwinckle, eds. American Phytopathological Society, St. Paul, MN.

Spotts, R., Holmes, R., and Washington, W. 1988. Factors affecting wet core rot of apples. Australas. Plant Pathol. 17:53.

Taiz, L., and Zeiger, E. 2002. Plant Physiology. Ch. 5, Mineral nutrition. Sinauer Associates Inc., Sunderland, MA, USA.

Tehranifar, A., Selahvarzi, Y., Kharrazi, M., and Bakhsh, V. J. 2011. High potential of agro-industrial by-products of pomegranate (Punica granatum L.) as the powerful antifungal and antioxidant substances. Ind. Crops Prod. 34:1523-1527

Tziros, G. T., Lagopodi, A., and Tzavella-Klonari, K. 2008. Alternaria alternate fruit rot of pomegranate (Punica granatum) in Greece. Plant Pathol. 57:379.

Vincent, A., Bartual, J., Mira, J. L., Beltran, V., and Palou, L. 2017. Control of black heart of cv. Wonderful pomegranate caused by Alternaria alternata in Spain. Page 89 in: Proc. of the ISHS 4th Internat. Symp. on Pomegranate and Minor Mediterranean Fruits. Elche, Spain.

Vylkova, S. 2017. Environmental pH modulation by pathogenic fungi as a strategy to conquer the host.Deborah A. Hogan, ed. PLOS Pathog. 13:e1006149.

Walters, D. R., and Bingham, I. J. 2007. Influence of nutrition on disease development caused by fungal pathogens: Implications for plant disease control. Ann. Appl. Biol. 151:307-324.

Zhang, L., and McCarthy, M. J. 2012. Black heart characterization and detection in pomegranate using NMR relaxometry and MR imaging. Postharvest Biol. Technol. 67:96-101. 